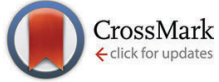

Cite this: J. Mater. Chem. C, 2015 , 3, 4698

\title{
A perylene diimide (PDI)-based small molecule with tetrahedral configuration as a non-fullerene acceptor for organic solar cells $\dagger$
}

\author{
Wangqiao Chen, $\ddagger^{\mathrm{ab}}$ Xuan Yang, $\ddagger^{\mathrm{c}}$ Guankui Long, ${ }^{\text {ac }}$ Xiangjian Wan, ${ }^{c}$ \\ Yongsheng Chen*c and Qichun Zhang*abd
}

Received 28th March 2015,

Accepted 2nd April 2015

DOI: $10.1039 / c 5 t c 00865 d$

www.rsc.org/MaterialsC

\begin{abstract}
In this paper, a new perylene diimide (PDI)-based acceptor $\mathbf{M e - P D I}{ }_{\mathbf{4}}$ with tetrahedral configuration (or 3D) has been synthesized and characterized. Solution-processed organic solar cells (OSCs) based on Me-PDI ${ }_{4}$ have been investigated and our results show that the device performance can reach as high as 2.73\%. Our new design with tetrahedral configuration (or 3D) could be an efficient approach to increase the PCE of OSCs with non-fullerene acceptors.
\end{abstract}

\section{Introduction}

Organic solar cells (OSCs) have been extensively investigated in the past decades due to their several charming advantages including low cost, light weight, easy processability, and flexibility. ${ }^{1,2}$ To complete the function of OSCs, both donor materials (holes as major charge carriers) and acceptor elements (electrons as major charge carriers) are required. Currently, many efforts have been devoted towards the design and synthesis of novel donor materials with low bandgap and high mobility. The finely-tuned donor structures have increased the Power Conversion Efficiency (PCE) to as high as $10 \%{ }^{3-5}$ However, as the counterpart of donor materials, the progress with acceptors is relatively lagging behind. Until now, fullerene and their derivatives ([6,6]-phenyl $\mathrm{C}_{61} / \mathrm{C}_{71}$ butyric acid methyl ester $\left(\mathrm{PC}_{61} \mathrm{BM}\right.$ and $\left.\left.\mathrm{PC}_{71} \mathrm{BM}\right)\right)$ are still the dominating acceptors. ${ }^{6-11}$ Unfortunately, fullerene systems have been recognized with several disadvantages for their practical applications including (a) a limited absorption spectrum compared

\footnotetext{
${ }^{a}$ School of Materials Science and Engineering, Nanyang Technological University, 50 Nanyang Avenue, Singapore 639798, Singapore. E-mail: qczhang@ntu.edu.sg

${ }^{b}$ Institute for Sports Research, Nanyang Technological University, 50 Nanyang Avenue, Singapore 639798, Singapore

${ }^{c}$ Key Laboratory of Functional Polymer materials, Center for Nanoscale Science and Technology, Institute of Polymer Chemistry, College of Chemistry, Collaborative Center of Chemical Science and Engineering (Tianjin), Nankai University, Tianjin, 300071, China. E-mail: yschen99@nankai.edu.cn

${ }^{d}$ Division of Chemistry and Biological Chemistry, School of Physical and Mathematical Sciences, Nanyang Technological University, Singapore 637371, Singapore

$\dagger$ Electronic supplementary information (ESI) available: General characterization, experimental details, DFT calculation of Me-PDI $_{4}$, complementary PCE data, optical simulation, TEM, SCLC, NMR and MS data, etc. See DOI: 10.1039/ c5tc00865d

\$ These two authors contribute equally to this work.
}

with the solar spectrum, (b) difficulty in functionalization and tuning of the electronic properties, which is realized only in a few cases such as the bis-adduct approach, ${ }^{12}$ and (c) high cost of production, especially for $\mathrm{PC}_{71} \mathrm{BM} .{ }^{13}$ Therefore, it is highly desirable to develop novel non-fullerene acceptors, which possess a strong absorption ability in the visible and NIR regions, adjustable energy levels, tunable electronic properties, and good match capability with donor materials.

The non-fullerene acceptor systems can be classified into two groups: (a) small molecules such as fluorinated phthalocyanines, diketopyrrolopyrroles, vinazene and 9, 9'-bifluororeylidene, and (b) conjugated polymers functionalized with strong electronwithdrawing groups such as fluorine, cyano and benzothiadiazole. However, both systems normally show poor PCEs $<3 \%$ or around $3 \%{ }^{14-29}$ Only in the last two years, larger PCEs (4-6\%) have been reported. ${ }^{30-40}$ These promising results strongly encourage scientists to search for other novel acceptor systems. Since perylene diimide (PDI) has been widely known as an n-type organic semiconductor with high chemical, thermal and light stabilities, PDIs should be good candidates to replace fullerene in OSCs. ${ }^{41,42}$ In addition, this type of materials generally shows strong absorption in the visible region or even in the NIR area as well as good electron-accepting ability due to their well-placed lowest unoccupied molecular orbital LUMO energy $(c a .-4.0 \mathrm{eV})$ and excellent electron mobility. ${ }^{43,44}$ More importantly, their solubility as well as optoelectronic and self-assembling properties could be finely tuned by appropriate modification. ${ }^{45,46}$ In fact, PDIs have been demonstrated as potential acceptors in OSCs and mono-PDI systems can reach PCE as high as $3 \% .{ }^{47-50}$ However, generally speaking, the performance of mono-PDI derivatives is not very promising due to their stronger aggregation resulting from the large intermolecular $\pi-\pi$ interaction..$^{51-53}$ To address this problem, various alkyl chains were introduced on the bay 
of the PDI, which did not improve their performance much in OSCs. ${ }^{54,55}$ Very recently, introducing the "twisted" concept in the PDI system to prohibit the aggregation has been investigated and the performance of OSCs based on these materials is very promising. ${ }^{52,56-58}$ For example, Yao's group introduced one thiophene as a bridge between two PDI units and achieved PCE as high as $4.03 \% .{ }^{59}$ After finely tuning the film parameter, the PCE can reach eventually up to $6.1 \% .^{30,31}$ Similarly, Zhao's and Zhan's group introduced other units (spirobifluorene, indaceno[1,2- $\left.b: 5,6-b^{\prime}\right]$ dithiophene, etc.) into PDI systems and obtained good PCEs of $2.35 \%$ and $2.61 \%$ by taking P3HT as the donor. ${ }^{56,60}$ Although these efforts are impressive, further improving the performance of PDIs in OSCs is still highly desirable. Given that fullerene has a ball-like structure, which might enable isotropic charge transport, ${ }^{61-63}$ designing novel non-fullerene molecules with a 3D architecture might enhance the performance of OSCs. In fact, several groups have conducted their research in this direction. For example, Zhan's group reported a novel acceptor with a quasi-3D non-planar structure with triphenylamine as a core to reach PCE as high as $3.32 \%{ }^{64,65}$ Yan's group also reported a novel small acceptor based on a tetraphenylethylene core to give a high PCE of $5.53 \% .{ }^{66}$ In Jenekhe's recent paper to summarize the guidelines to design novel acceptors, he emphasized the importance of 3D architecture. $^{32}$ These results and points make us believe that acceptors with $3 \mathrm{D}$ configuration could be an efficient approach to increase the PCE of OSCs.

It is well-known that tetraphenyl methane possesses a tetrahedral architecture and it has been widely used to build porous polyimides with high surface areas for catalysis and gas storage applications. ${ }^{67-69}$ By employing this building block as a core and attaching PDIs on it, ${ }^{70,71}$ a novel acceptor with 3D configuration could be constructed. Herein, we report a new non-fullerene acceptor (Me-PDI ${ }_{4}$ ) with $3 \mathrm{D}$ configuration and test its photovoltaic performance with donor material poly[4,8-bis-(2-ethylhexyloxy)benzo[1,2- $\left.b: 4,5-b^{\prime}\right]$ dithiophene-2,6-diyl-alt-4-(2-ethylhexyloxy-1-one)thieno[3,4- $b]$ thiophene-2-yl-2-ethylhexan-1-one] (PBDTTT-C-T), which has been frequently used in previous studies. ${ }^{58,72}$ The solutionprocessed BHJ OSCs based on Me-PDI $\mathbf{H}_{4}$ show a PCE as high as $2.73 \%$. Our results further demonstrate that designing acceptors with 3D architecture should be an effective strategy to improve the PCE performance.

\section{Experimental section}

\section{Synthesis of Me-PDI}

A mixture of $\mathbf{M}_{\mathbf{4}}$ (403 $\mathrm{mg}, 0.60 \mathrm{mmol}$ ), tetrakis(4-aminophenyl) methane (51 mg, $0.135 \mathrm{mmol}$ ), and a small spoon of anhydrous $\mathrm{Zn}(\mathrm{OAc})_{2}$ was refluxed in $10 \mathrm{~mL}$ quinoline solution for 36 hours until the reaction was complete. Then, the reaction solution was dropped into $2 \mathrm{~N}$ diluted $\mathrm{HCl}$ solution and stirred for about $20 \mathrm{~min}$. The red precipitated solid was filtrated and washed with $\mathrm{H}_{2} \mathrm{O}$ several times and then with methanol. The rough product was dried in a vacuum oven and further purified by column chromatography by using chloroform: methanol (100:1.5 V:V) as the eluent. Deep red solid, $221 \mathrm{mg}$, yield: 55\%. ${ }^{1} \mathrm{H}$ NMR $\left(400 \mathrm{~Hz}, \mathrm{CDCl}_{3}\right): 8.43(\mathrm{~m}, 16 \mathrm{H}$, perylene aryl $\mathrm{H}), 8.09-8.07$ $(\mathrm{m}, 16 \mathrm{H}$, perylene aryl $\mathrm{H}), 7.65-7.57(\mathrm{~m}, 16 \mathrm{H}$, aromatic $\mathrm{H})$, 4.18 (m, 8H), 2.01 (m, 4H), 1.36-1.21 (m, 128H), 0.84-0.81 $(\mathrm{m}, 24 \mathrm{H}) .{ }^{13} \mathrm{C}$ NMR $\left(100 \mathrm{~Hz}, \mathrm{CDCl}_{3}\right): 163.1,162.7,148.7$, 133.6 , 133.2, 130.6, 133.6, 133.2, 130.6, 128.5, 128.1, 130.6, 128.5, 128.1, 15.2, 123.1, 123.0, 122.6, 64.8, 44.8, 36.7, 30.1, 29.7, 29.6, 29.3, 26.5, 22.6, 14.0. MALDI-TOF MS: calculated for $\mathrm{C}_{201} \mathrm{H}_{212} \mathrm{~N}_{8} \mathrm{O}_{16}+\mathrm{H}^{+}$, 2993.60; found: 2994.61. Elemental analysis: calculated $\mathrm{C}_{201} \mathrm{H}_{212} \mathrm{~N}_{8} \mathrm{O}_{16}, \mathrm{C}: 80.58, \mathrm{H}: 7.13, \mathrm{~N}: 3.74$; experimental data: $\mathrm{C}: 80.72, \mathrm{H}: 7.21, \mathrm{~N}: 3.99$.

\section{Device fabrication and measurements}

The conventional photovoltaic devices were fabricated with the structure of glass/ITO/PEDOT:PSS/PBDTTT-C-T:Me-PDI 4 /Ca/Al. Patterned ITO-coated substrates with a sheet resistance of $\sim 15$ ohm per square were cleaned using a detergent scrub and subsequently subjected to ultrasonic treatment in soap deionized water, deionized water, acetone and isopropyl alcohol for 15 minutes in each step. After drying by a nitrogen flow, the ITO substrates were treated with ultraviolet-ozone for 20 minutes. A thin layer (ca. $30 \mathrm{~nm}$ ) of PEDOT:PSS (Clevios P VP AI 4083, filtered at $0.45 \mu \mathrm{m}$ ) was then spin-coated at $4500 \mathrm{rpm}$ onto ITO substrates. After baking at $150{ }^{\circ} \mathrm{C}$ for 20 minutes under ambient conditions, the substrates were transferred into an argon-filled glovebox. Subsequently, a PBDTTT-C-T:Me-PDI ${ }_{4}$ blend solution in ortho-dichlorobenzene $\left(1: 1 \mathrm{w} / \mathrm{w}\right.$, in total $\left.30 \mathrm{mg} \mathrm{mL}^{-1}\right)$ with different contents of DIO additive was spin-coated onto the PEDOT:PSS layer at $1500 \mathrm{rpm}$. After thermal annealing at different temperatures for 10 minutes, a $20 \mathrm{~nm}$ Ca layer and a $100 \mathrm{~nm} \mathrm{Al}$ layer were subsequently deposited on the active layer under high vacuum $\left(<2 \times 10^{-4} \mathrm{~Pa}\right)$.

The inverted devices were fabricated with the structure of glass/ ITO/ZnO nanoparticles (NPs)/PBDTTT-C-T:Me-PDI ${ }_{4} /$ modified PEDOT:PSS/Ag. ZnO NPs were prepared using the techniques reported by Beek et al. ${ }^{73}$ The $\mathrm{ZnO} \mathrm{NP}$ solution (in $n-\mathrm{BuOH}, 3000 \mathrm{rpm}$, filtered at $0.22 \mu \mathrm{m}, \sim 30 \mathrm{~nm}$ ) was spin-coated onto the pre-cleaned ITO substrates. After being baked at $120{ }^{\circ} \mathrm{C}$ for 30 minutes, the substrates were transferred into an argon-filled glove box. The active layer solution was subsequently spin-coated onto the ZnO layer under the same conditions using the conventional device. Then the modified PEDOT:PSS ${ }^{74,75}$ was spin-coated onto the active layer, followed by thermal annealing at $100{ }^{\circ} \mathrm{C}$ for 10 minutes. Finally, a $100 \mathrm{~nm} \mathrm{Ag}$ layer was deposited on the active layer under high vacuum $\left(<2 \times 10^{-4} \mathrm{~Pa}\right)$. The effective area of each cell was about $4 \mathrm{~mm}^{2}$ defined by shadow masks. The thicknesses of the active layer and ZnO NPs were measured using a Dektak 150 profilometer.

The current density-voltage $(J-V)$ curves of photovoltaic devices were obtained using a Keithley 2400 source-measure unit. The photocurrent was measured under illumination simulated $100 \mathrm{~mW} \mathrm{~cm} \mathrm{~cm}^{-2}$ AM 1.5G irradiation using a xenon-lamp-based solar simulator [Oriel 96000 (AM1.5G)] in an argon filled glove box, calibrated with a standard Si solar cell. The external quantum efficiency (EQE) value of the encapsulated device was obtained using a halogen-tungsten lamp, monochromator, optical 
chopper, and Stanford Research Systems SR810 lock-in amplifier in air, and the photon flux was determined using a calibrated silicon photodiode.

\section{Optical simulations}

The optical simulation was modeled using a transfer matrix model (TMM), the MATLAB program is available online at http://web.stanford.edu/group/mcgehee/transfermatrix/index.html. The one-dimensional spatial distribution of normalized incident light intensity $\left(|E|^{2}\right)$ inside the devices was calculated by means of an optical TMM approach. The spatial distribution of the absorbed photon flux density could then be calculated by integrating singlewavelength $|E|^{2}$ with an AM 1.5G spectrum from $300 \mathrm{~nm}$ to $800 \mathrm{~nm}$. Finally, the theoretical maximum $J_{\mathrm{sc}}$ for a device under AM 1.5G illumination was determined by spatially integrating the absorbed photon flux density within the active layer, assuming $100 \%$ internal quantum efficiency for all wavelengths.

\section{Results and discussion}

\section{Synthesis}

As shown in Scheme 1, Me-PDI $\mathbf{4}_{\mathbf{4}}$ was synthesized by refluxing the mixture of tetrakis(4-aminophenyl) methane and $\mathbf{M}_{\mathbf{4}}$ in a quinoline solution at $180{ }^{\circ} \mathrm{C}$, using a small amount of anhydrous $\mathrm{Zn}(\mathrm{OH})_{2}$ as the catalyst. For the precursor $\mathbf{M}_{4}$, to avoid the tedious work of purification through column chromatography, we alternatively synthesized it based on several literature procedures ${ }^{76-79}$ (Fig. S1, ESI $\dagger$ ). The as-prepared deep red product Me-PDI $_{4}$ was obtained in 55\% yield after purification and fully characterized by ${ }^{1} \mathrm{H}$ NMR, ${ }^{13} \mathrm{C}$ NMR and MALDI-TOF (Fig. S7 and S8, ESI $\dagger$ ). Importantly, Me-PDI ${ }_{4}$ displays very good solubility ( $>20 \mathrm{mg} \mathrm{mL}^{-1}$ ) in various common solvents including methylene chloride, chloroform, chlorobenzene and dichlorobenzene.

\section{Thermal properties}

The thermal properties of $\mathbf{M e -} \mathbf{P D I}_{\mathbf{4}}$ were investigated by thermogravimetric analysis (TGA) and differential scanning calorimetry (DSC) as shown in Fig. 1. From the TGA graph, it can be seen that

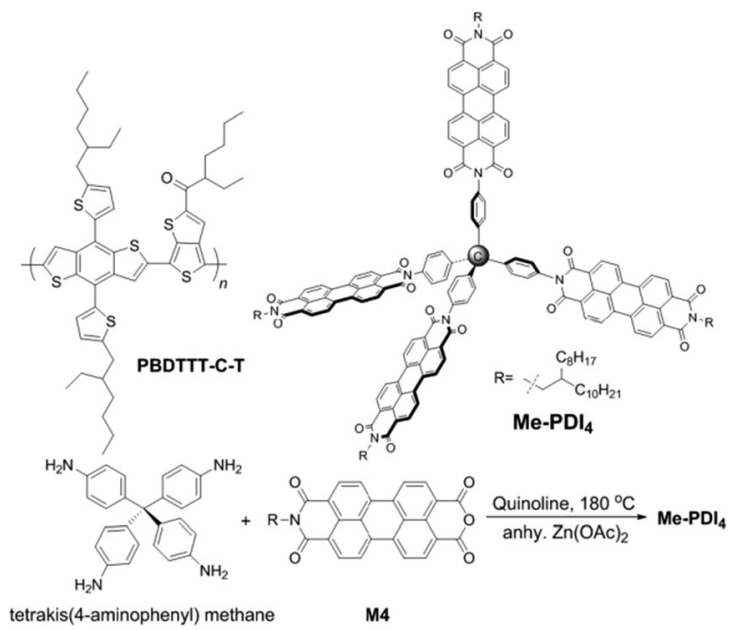

Scheme 1 Structure of PBDTTT-C-T and synthesis of Me-PDI $_{4}$.
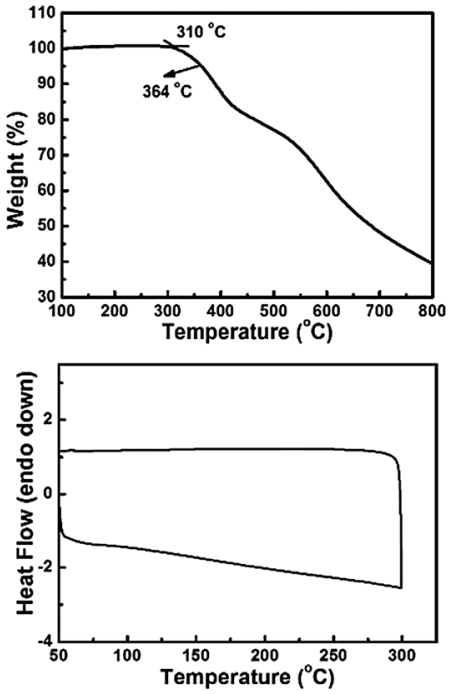

Fig. 1 TGA and DSC spectra of $\mathrm{Me}^{-\mathrm{PDI}_{4}}$

Me-PDI 4 can be stable up to $310{ }^{\circ} \mathrm{C}$, with $5 \%$ weight loss at $364{ }^{\circ} \mathrm{C}$. The DSC spectrum indicates that there is no phase transition peak ascribed to melting or crystallinity between $50{ }^{\circ} \mathrm{C}$ and $300{ }^{\circ} \mathrm{C}$, suggesting Me-PDI $\mathbf{M}_{4}$ is amorphous.

\section{Simulation of Me-PDI}

The geometry of $\mathbf{M e}^{-P_{D I}} \mathbf{I}_{\mathbf{4}}$ was optimized using DFT calculations (B3LYP/6-31G*), ${ }^{80,81}$ and the frequency analysis was followed to ensure that the optimized structures were stable states. To simplify the calculation, the longer alkyl groups were replaced by ethyl groups and all calculations were carried out using Gaussian 09. ${ }^{89}$

The Me-PDI ${ }_{4}$ molecule has very high symmetry with a point group of $S 4$, and symmetry constraints were used in the DFT calculation. The dihedral angle between the PDI unit and the connected phenyl group is $110.17^{\circ}$, which indicates that four PDI units were separated by the tetraphenyl methane core. Therefore, this molecule has four degenerated LUMOs which can accept up to eight electrons (as shown in Fig. 2, the electron density distributions for the degenerated LUMOs and highest occupied molecular orbitals (HOMOs) are shown in Fig. S2, ESI $\dagger$ ).

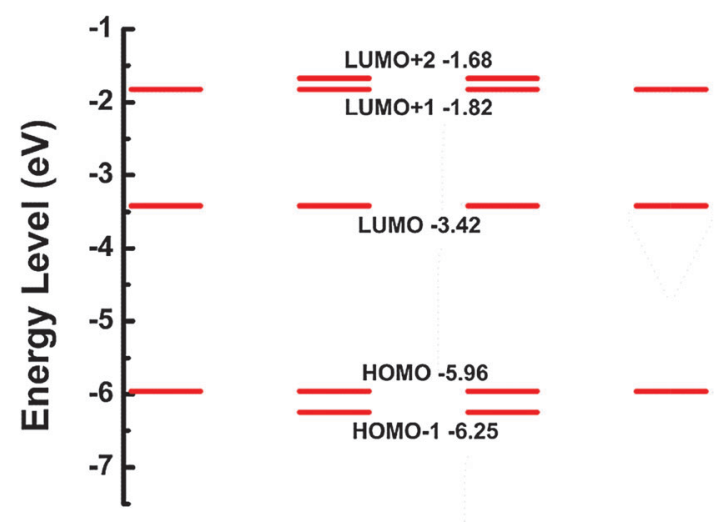

Fig. 2 Theoretical calculations of energy levels. 


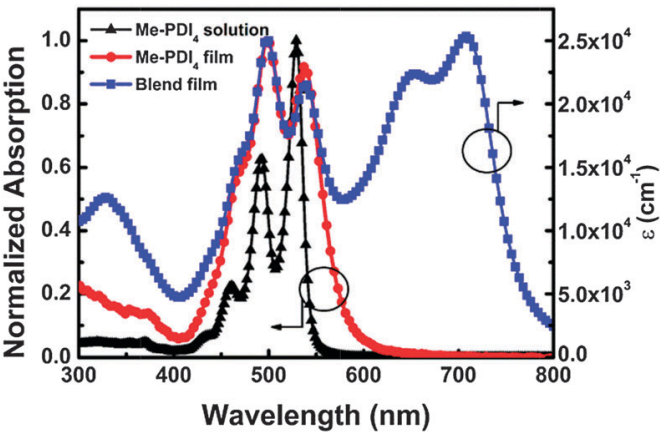

Fig. 3 UV-vis absorption spectra of $\mathbf{M e}^{-P} \mathbf{I}_{4}$ in solution, film and $\mathbf{M e}$ $\mathrm{PDI}_{4}$ :PBDTTT-C-T blend film. $\varepsilon$ : refers to the absorption coefficient.

This predicted result is similar to that of the famous acceptor $\mathrm{PC}_{61} \mathrm{BM}$, which has three quasi-degenerated LUMOs. ${ }^{13}$ Besides this, the 3D architecture of $\mathbf{M e -}-\mathbf{P D I}_{\mathbf{4}}$ could facilitate the multiconjugation with the neighbor molecules, therefore increasing the electron-couplings during charge transfer. Based on these

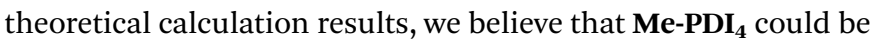
a promising electron acceptor in OPVs.

\section{Electronic and optical properties}

The normalized UV-vis absorption spectra of $\mathbf{M e - P D I}{ }_{4}$ in dilute chloroform and in a solid film are shown in Fig. 3. In solution, Me-PDI 4 shows a narrow absorption range from $420-550 \mathrm{~nm}$, along with two peaks at $490 \mathrm{~nm}$ and $530 \mathrm{~nm}$. The maximum molar absorption coefficient at $530 \mathrm{~nm}$ is $4.956 \times 10^{4} \mathrm{M}^{-1} \mathrm{~cm}^{-1}$. Compared with the absorption in solution, the thin film of Me-PDI $\mathbf{P}_{\mathbf{4}}$ shows a broader absorption with a similar profile. Only a $9 \mathrm{~nm}$ redshift of the absorption peak from solution to film suggests that there are weak intermolecular interactions and molecular aggregation in the film. As for the absorption of the PBDTTT-C-T:Me-PDI $\mathbf{4}_{4}$ blend film, a complementary UV-vis absorption covering almost the whole visible range (from $300 \mathrm{~nm}$ to 780 ) is observed. This feature may suggest that the active layer could absorb as many photons as possible, which should have a big contribution to a better short circuit-current density $\left(J_{\text {sc }}\right)$ of the photovoltaic device.

The electrochemical properties of Me-PDI ${ }_{4}$ were studied by cyclic voltammetry $(\mathrm{CV})$ in $0.1 \mathrm{M} n$ - $\mathrm{Bu}_{4} \mathrm{NPF}_{6}$ methylene chloride solution. The reduction wave of the cyclic voltammogram is shown in Fig. 4a, and the calculated energy levels are summarised in Table 1. It can be seen that the onset of reduction potential versus $\mathrm{FeCp}_{2}{ }^{+/ 0}(+0.48 \mathrm{~V})$ was about $-0.98 \mathrm{~V}$. Thus, the LUMO energy was estimated to be $-3.82 \mathrm{eV}$ from the reduction potential by using the empirical formula, $E_{\mathrm{LUMO}}=-\left(E_{\text {red,onset }}+\right.$ 4.8) $\mathrm{eV}$, assuming the absolute energy level of $\mathrm{FeCp}_{2}{ }^{+/ 0}$ to be $4.8 \mathrm{eV}$ below vacuum. ${ }^{82}$ The HOMO of Me-PDI ${ }_{4}$ is $-5.96 \mathrm{eV}$ calculated from LUMO and $E_{\mathrm{g}}^{\text {opt }}$, which is consistent with the DFT calculation result $(-5.958 \mathrm{eV})$. The alignment of the energy levels of donor material PBDTTT-C-T with acceptor material Me-PDI 4 is shown in Fig. 4b. Given that the LUMO value of PBDTTT-C-T is $-3.25 \mathrm{eV}$, the offset between the LUMO of the donor and the LUMO of the acceptor is calculated to be $0.56 \mathrm{eV}$, which is large enough to drive the exciton separation and (a)

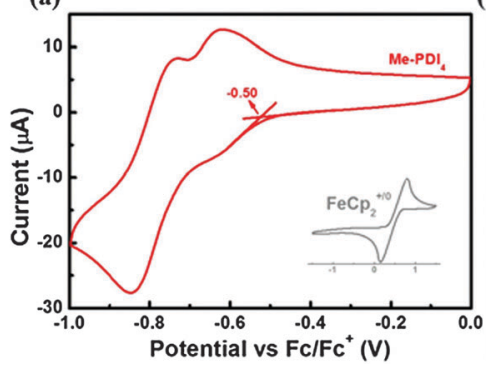

(b)

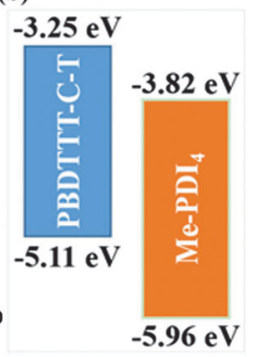

Fig. 4 (a) Cyclic voltammogram for $\mathrm{Me}^{-\mathrm{PDI}_{4}}$ and (b) energy levels of the donor PBDTTT-C-T and the acceptor $\mathbf{M e - P D I}$.

Table 1 Summary of optical properties and energy levels of $\mathbf{M e}-\mathrm{PDI}_{\mathbf{4}}$

\begin{tabular}{lcccc}
\hline & $\lambda_{\text {onset }}{ }^{a}[\mathrm{~nm}]$ & $\mathrm{LUMO}^{b}[\mathrm{eV}]$ & $E_{\mathrm{g}}^{\mathrm{opt} c}[\mathrm{~nm}]$ & $\mathrm{HOMO}^{d}[\mathrm{eV}]$ \\
\hline Me-PDI $_{4}$ & 580 & -3.82 & 2.14 & -5.96 \\
${ }^{a}$ Obtained from film absorption. ${ }^{b}$ Measured by cyclic voltammetry. \\
${ }^{c}$ Estimated based on the film absorption onset. ${ }^{d}$ Calculated using \\
LUMO and $E_{\mathrm{g}}^{\mathrm{opt}}$.
\end{tabular}

electron transportation within the active layer since the generally accepted minimal value for such offset to guarantee success of these processes is around $0.3 \mathrm{eV}^{83}$

\section{Photovoltaic performances of the devices}

In order to demonstrate the potential application of Me-PDI $_{4}$ in OSCs, we fabricated solution-processed OSCs based on PBDTTTC-T:Me-PDI ${ }_{4}$ and evaluated the current density-voltage $(J-V)$ characteristics under AM1.5 solar illumination at $100 \mathrm{~mW} \mathrm{~cm} \mathrm{~cm}^{-2}$. The device performance and corresponding $J-V$ curves are summarized in Table 2 and Fig. 5a, respectively. More detailed device performances are summarized in Fig. S3, ESI $\dagger$. A conventional structure of indium tin oxide (ITO)/poly(3,4-ethylenedioxythiophene):poly(styrenesulfonate) (PEDOT:PSS)/PBDTTT-C-T:Me-PDI 4 $\mathrm{Ca} / \mathrm{Al}$ was firstly fabricated. Without any additive and post annealing treatment, the device shows a low PCE of $0.92 \%$, with an open circuit voltage $\left(V_{o c}\right)$ of $0.71 \mathrm{~V}$, a short circuit current density $\left(J_{\mathrm{sc}}\right)$ of $3.74 \mathrm{~mA} \mathrm{~cm}^{-2}$ and a fill factor $(\mathrm{FF})$ of 0.345 . After adding $3 \%(\mathrm{v} / \mathrm{v})$ 1,8-diiodooctane (DIO), FF increased moderately and $J_{\mathrm{sc}}$ increased significantly from $3.74 \mathrm{~mA} \mathrm{~cm}^{-2}$ to $6.66 \mathrm{~mA} \mathrm{~cm} \mathrm{~cm}^{-2}$ at $3 \%$ DIO, and the best device performance with a PCE of

Table 2 Summary of the best device performance based on PBDTTT-C$\mathrm{T}: \mathbf{M e}-\mathrm{PDI}_{4}$. The values in parentheses refer to the average PCEs obtained from over 10 devices

\begin{tabular}{lllll}
\hline DIO [\%] & $V_{\text {oc }}[\mathrm{V}]$ & $J_{\text {sc }}\left[\mathrm{mA} \mathrm{cm}^{2}\right]$ & FF $[\%]$ & PCE [\%] \\
\hline 0 & 0.71 & 3.74 & 34.5 & $0.92(0.90)$ \\
1 & 0.75 & 4.07 & 38.9 & $1.19(1.17)$ \\
3 & 0.76 & 6.66 & 40.4 & $2.04(1.98)$ \\
5 & 0.77 & 3.31 & 42.0 & $1.07(1.00)$ \\
$3^{a}$ & 0.77 & 6.47 & 47.2 & $2.35(2.25)$ \\
$3^{b}$ & 0.77 & 7.83 & 45.0 & $2.73(2.47)$
\end{tabular}

${ }^{a}$ Conventional device with thermal annealing at $180{ }^{\circ} \mathrm{C}$ for $10 \mathrm{~min}$. ${ }^{b}$ Inverted device based on optimal conditions. 

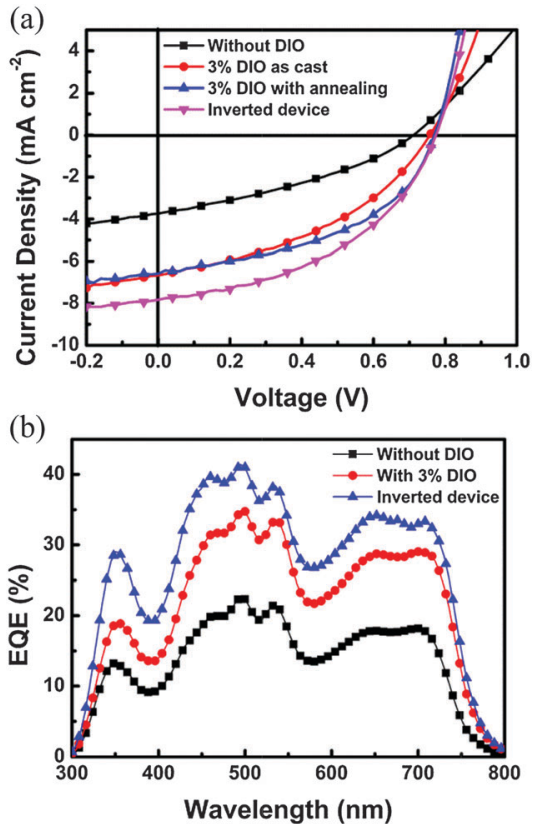

Fig. 5 (a) $J-V$ curves of devices and (b) EQE spectra of the blend films.

$2.04 \%$ was obtained. Thermal annealing is a widely used method to optimize the morphology of the active layer. ${ }^{84}$ Thus, at the optimal DIO content of $3 \%$, different thermal annealing temperatures were studied. (Fig. S3, ESI $\dagger$ ) At a relatively high annealing temperature of $180{ }^{\circ} \mathrm{C}$, the PCE enhanced to $2.35 \%$ mainly due to the increased FF (0.472). Recently, inverted solar cells have been demonstrated as an effective structure to further improve the OSC performance. ${ }^{32,37,85}$ In order to further increase the device performance, an inverted device with a structure of ITO/zinc oxide (ZnO) nanoparticles/PBDTTT-C-

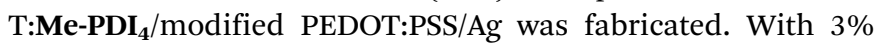
DIO concentration and $180{ }^{\circ} \mathrm{C}$ thermal annealing temperature, the inverted device shows a PCE of $2.73 \%$, which is apparently higher than that of the conventional device and is mainly ascribed to the enhancement of $J_{\mathrm{sc}}$ (from 6.47 to $7.83 \mathrm{~mA}$ $\mathrm{cm}^{-2}$ ). In view of that both conventional and inverted devices exhibit similar $\mathrm{FF}$, which indicates that there is similar recombination in both devices, it is speculated that the increased $J_{\mathrm{sc}}$ is mainly ascribed to the enhanced absorption of photons in the active layer with the introduction of the inverted device. In order to further confirm this, optical simulations were performed in both conventional and inverted devices based on real device conditions, and it was found that more excitons were generated in the inverted device than the conventional device (as shown in Fig. S4, ESI $\dagger$ ).

The external quantum efficiency (EQE) spectra of PBDTTT-CT:Me-PDI ${ }_{4}$ blend films (Fig. $5 \mathrm{~b}$ ) are consistent with the $J_{\mathrm{sc}}$ variation of $J-V$ characteristics. Corresponding with the broad UV-vis absorption range of the blend film, the EQE spectra show a wide range photo response from $300-800 \mathrm{~nm}$. The photo response ranging from $400-550 \mathrm{~nm}$, which is attributed to the absorption of Me-PDI ${ }_{4}$, indicates that Me-PDI ${ }_{4}$ makes a considerable contribution to the overall photocurrent of the whole device. The EQE at $500 \mathrm{~nm}$ of the inverted device shows the highest value of $40 \%$, which is even higher than that in the range of $600-750 \mathrm{~nm}$ (resulting from the absorption of PBDTTT-C-T). The calculated $J_{\mathrm{sc}}$ integrated from the EQE spectrum of the conventional device processed without DIO, with $3 \%$ DIO and the inverted device is 4.004, 6.464 and $7.825 \mathrm{~mA} \mathrm{~cm}^{-2}$, which shows $7 \%, 3 \%$ and $1 \%$ mismatch with that obtained by $J-V$ measurements, respectively.

\section{Morphological properties}

In order to elucidate the impact of DIO content and thermal annealing on device performance, atomic force microscopy (AFM) in the tapping mode and transmission electron microscopy (TEM) were carried out to study the morphology changes. Fig. 6 presents the AFM height and corresponding phase images. For the film treated without DIO, there was no obvious phase separation and a relatively small root mean square (rms) roughness $(0.695 \mathrm{~nm})$ is obtained. Using DIO as an additive to treat the blend film led to a change in film morphology, resulting in the formation of a particle-like domain and the rms roughness increased to $0.884 \mathrm{~nm}$. The phase image confirmed the improved phase separation and the diameter of the bright domain increased to about $40 \mathrm{~nm}$. The TEM result (Fig. S5, ESI $\dagger$ ) was consistent with this morphology change. With the increased donor-acceptor in the interfacial area, the $J_{\mathrm{sc}}$ was enhanced from 3.74 to $6.66 \mathrm{~mA} \mathrm{~cm}{ }^{-2} .86,87$ Based on $3 \%$ DIO, further thermal annealing causes a more uniform interpenetrating network along
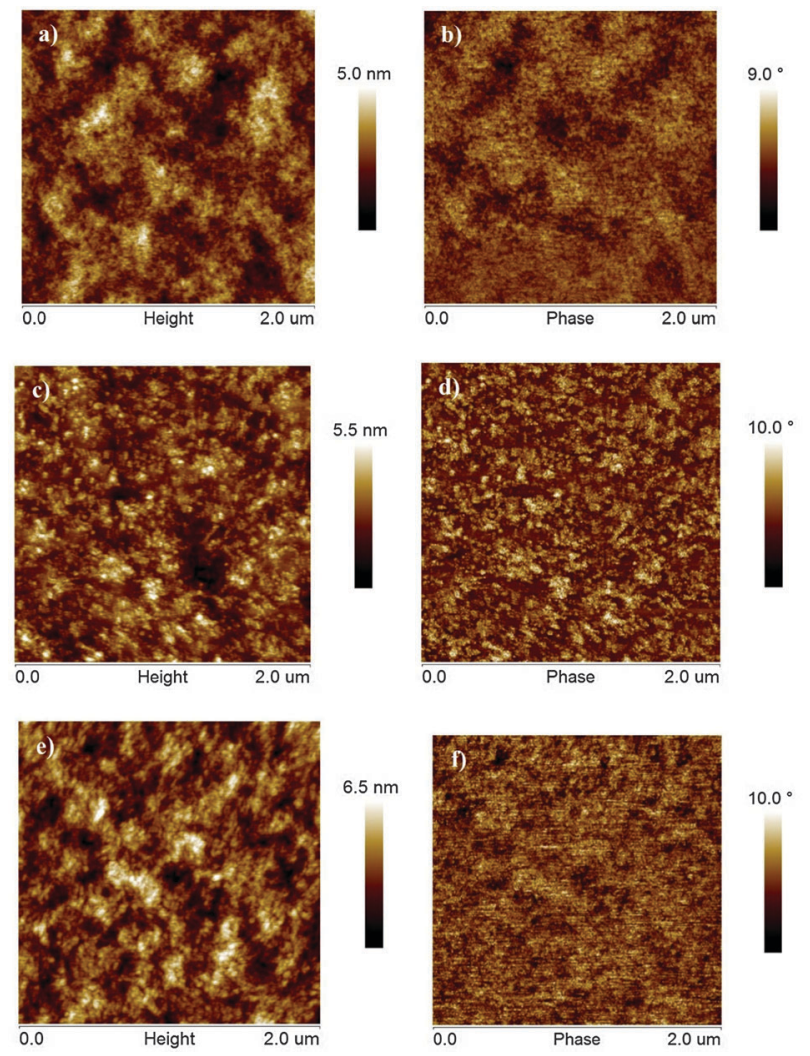

Fig. 6 AFM height $(a, c, e)$ images and corresponding phase $(b, d, f)$ images of PBDTTT-C-T:Me-PDI ${ }_{4}$ blend film treated without DIO (a, b), with 3\% DIO (c, d) and with $3 \% \mathrm{DIO}$ and $180{ }^{\circ} \mathrm{C}$ thermal annealing (e, f). 
with a rms roughness of $0.964 \mathrm{~nm}$, which may account for the increment of FF (from 0.404 to 0.472 ). We infer that the improvement of phase separation with the treatment of DIO can be attributed to the high boiling point of DIO $\left(332.5{ }^{\circ} \mathrm{C}\right.$ at $\left.1 \mathrm{~atm}\right)$ and

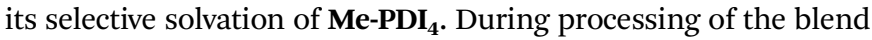
films, the slow evaporation speed of DIO may offer sufficient time for the more soluble acceptor to form larger phase domains and produce more favorable phase separation. ${ }^{59}$

\section{Charge transport properties}

Carrier transport properties were investigated by measuring the hole and electron mobility of the PBDTTT-C-T:Me-PDI 4 blend film using the space charge limited current (SCLC) method. The results under different conditions and the fitting curves of the hole-only device and the electron-only device are presented in Fig. S6 (ESI $\dagger$ ). These results show that the as-prepared film under optimal conditions has a relatively low hole mobility of $5.55 \times 10^{-5} \mathrm{~cm}^{2} \mathrm{~V}^{-1} \mathrm{~s}^{-1}$ and a lower electron mobility of $1.78 \times 10^{-6} \mathrm{~cm}^{2} \mathrm{~V}^{-1} \mathrm{~s}^{-1}$. The unbalanced electron-hole mobility $\left(\mu_{\mathrm{e}} / \mu_{\mathrm{h}}=0.032\right)$ may be responsible for the relatively low FF $(<0.5) .{ }^{88}$ The work on the enhancement of charge carrier mobility as well as the realization of balanced electron-hole mobility is still under investigation.

\section{Conclusions}

In conclusion, a novel non-fullerene acceptor based on PDIs with a 3D configuration was firstly explored and the as-prepared acceptor exhibits a complementary absorption and an appropriate energy level to the donor material. Solution-processed OSCs based on PBDTTT-C-T and Me-PDI 4 ( $1: 1 \mathrm{w} / \mathrm{w}$ with $3 \%$ DIO, annealing) could reach a better PCE as high as $2.73 \%$, which demonstrates that the $3 \mathrm{D}$ architecture could be an effective strategy for future design of novel acceptors.

\section{Acknowledgements}

Q.Z. acknowledges the financial support from AcRF Tier 1 (RG 16/12) from MOE, MOE Tier 2 (ARC 20/12 and ARC 2/13), and CREATE program (Nanomaterials for Energy and Water Management) from NRF, Singapore.

\section{Notes and references}

1 Y. Z. Lin, Y. F. Li and X. W. Zhan, Chem. Soc. Rev., 2012, 41, 4245.

2 Y. J. Cheng, S. H. Yang and C. S. Hsu, Chem. Rev., 2009, 109, 5868.

3 J. B. You, L. T. Dou, K. Yoshimura, T. Kato, K. Ohya, T. Moriarty, K. Emery, C. C. Chen, J. Gao, G. Li and Y. Yang, Nat. Commun., 2013, 4, 1446.

4 J.-D. Chen, C. Cui, Y.-Q. Li, L. Zhou, Q.-D. Ou, C. Li, Y. Li and J.-X. Tang, Adv. Mater., 2015, 27, 1035.

5 B. Kan, M. Li, Q. Zhang, F. Liu, X. Wan, Y. Wang, W. Ni, G. Long, X. Yang, H. Feng, Y. Zuo, M. Zhang, F. Huang,
Y. Cao, T. P. Russell and Y. Chen, J. Am. Chem. Soc., 2015, 137, 3886.

6 J. Y. Zhou, Y. Zuo, X. J. Wan, G. K. Long, Q. Zhang, W. Ni, Y. S. Liu, Z. Li, G. R. He, C. X. Li, B. Kan, M. M. Li and Y. S. Chen, J. Am. Chem. Soc., 2013, 135, 8484.

7 X. G. Guo, N. J. Zhou, S. J. Lou, J. Smith, D. B. Tice, J. W. Hennek, R. P. Ortiz, J. T. L. Navarrete, S. Y. Li, J. Strzalka, L. X. Chen, R. P. H. Chang, A. Facchetti and T. J. Marks, Nat. Photonics, 2013, 7, 825.

8 C. Z. Li, C. Y. Chang, Y. Zang, H. X. Ju, C. C. Chueh, P. W. Liang, N. Cho, D. S. Ginger and A. K. Y. Jen, Adv. Mater., 2014, 26, 6262.

9 Z. C. He, C. M. Zhong, S. J. Su, M. Xu, H. B. Wu and Y. Cao, Nat. Photonics, 2012, 6, 591.

10 S. H. Liao, H. J. Jhuo, Y. S. Cheng and S. A. Chen, Adv. Mater., 2013, 25, 4766.

11 A. K. K. Kyaw, D. H. Wang, D. Wynands, J. Zhang, T. Q. Nguyen, G. C. Bazan and A. J. Heeger, Nano Lett., 2013, 13, 3796.

12 Y. J. He, H. Y. Chen, J. H. Hou and Y. F. Li, J. Am. Chem. Soc., 2010, 132, 1377.

13 Y. J. He and Y. F. Li, Phys. Chem. Chem. Phys., 2011, 13, 1970. 14 Y. Z. Lin and X. W. Zhan, Mater. Horiz., 2014, 1, 470.

15 C. L. Chochos, N. Tagmatarchis and V. G. Gregoriou, RSC Adv., 2013, 3, 7160.

16 A. F. Eftaiha, J. P. Sun, I. G. Hill and G. C. Welch, J. Mater. Chem. A, 2014, 2, 1201.

17 X. W. Zhan, Z. A. Tan, B. Domercq, Z. S. An, X. Zhang, S. Barlow, Y. F. Li, D. B. Zhu, B. Kippelen and S. R. Marder, J. Am. Chem. Soc., 2007, 129, 7246.

18 H. T. Bai, Y. F. Wang, P. Cheng, J. Y. Wang, Y. Wu, J. H. Hou and X. W. Zhan, J. Mater. Chem. A, 2015, 3, 1910.

19 Y. Z. Lin, Y. F. Li and X. W. Zhan, Adv. Energy Mater., 2013, 3, 724.

20 P. Cheng, L. Ye, X. G. Zhao, J. H. Hou, Y. F. Li and X. W. Zhan, Energy Environ. Sci., 2014, 7, 1351.

21 T. V. Pho, F. M. Toma, B. J. T. de Villers, S. Wang, N. D. Treat, N. D. Eisenmenger, G. M. Su, R. C. Coffin, J. D. Douglas, J. M. J. Frechet, G. C. Bazan, F. Wudl and M. L. Chabinyc, Adv. Energy Mater., 2014, 4, 1301007.

22 H. Huang, N. J. Zhou, R. P. Ortiz, Z. H. Chen, S. Loser, S. M. Zhang, X. G. Guo, J. Casado, J. T. L. Navarrete, X. G. Yu, A. Facchetti and T. J. Marks, Adv. Funct. Mater., 2014, 24, 2782.

23 A. M. Poe, A. M. Della Pelle, A. V. Subrahmanyam, W. White, G. Wantz and S. Thayumanavan, Chem. Commun., 2014, 50, 2913.

24 H. Patil, W. X. Zu, A. Gupta, V. Chellappan, A. Bilic, P. Sonar, A. Rananaware, S. V. Bhosale and S. V. Bhosale, Phys. Chem. Chem. Phys., 2014, 16, 23837.

25 X. Wang, J. H. Huang, Z. X. Niu, X. Zhang, Y. X. Sun and C. L. Zhan, Tetrahedron, 2014, 70, 4726.

26 S. Subramaniyan, T. Earmme, N. M. Murari and S. A. Jenekhe, Polym. Chem., 2014, 5, 5707.

27 I. H. Jung, W. Y. Lo, J. Jang, W. Chen, D. L. Zhao, E. S. Landry, L. Y. Lu, D. V. Talapin and L. P. Yu, Chem. Mater., 2014, 26, 3450. 
28 X. L. Zhang, B. Jiang, X. Zhang, A. L. Tang, J. H. Huang, C. L. Zhan and J. N. Yao, J. Phys. Chem. C, 2014, 118, 24212.

29 J. H. Huang, X. Wang, X. Zhang, Z. X. Niu, Z. H. Lu, B. Jiang, Y. X. Sun, C. L. Zhan and J. N. Yao, ACS Appl. Mater. Interfaces, 2014, 6, 3853.

30 Z. H. Lu, B. Jiang, X. Zhang, A. L. Tang, L. L. Chen, C. L. Zhan and J. N. Yao, Chem. Mater., 2014, 26, 2907.

31 X. Zhang, C. L. Zhan and J. N. Yao, Chem. Mater., 2015, 27, 166.

32 H. Y. Li, T. Earmme, G. Q. Ren, A. Saeki, S. Yoshikawa, N. M. Murari, S. Subramaniyan, M. J. Crane, S. Seki and S. A. Jenekhe, J. Am. Chem. Soc., 2014, 136, 14589.

33 T. Earmme, Y. J. Hwang, S. Subramaniyan and S. A. Jenekhe, Adv. Mater., 2014, 26, 6080.

34 B. Verreet, K. Cnops, D. Cheyns, P. Heremans, A. Stesmans, G. Zango, C. G. Claessens, T. Torres and B. P. Rand, Adv. Energy Mater., 2014, 4, 1301413.

35 N. Beaumont, J. S. Castrucci, P. Sullivan, G. E. Morse, A. S. Paton, Z. H. Lu, T. P. Bender and T. S. Jones, J. Phys. Chem. C, 2014, 118, 14813.

36 D. Mori, H. Benten, I. Okada, H. Ohkita and S. Ito, Adv. Energy Mater., 2014, 4, 1301006.

37 Y. Zang, C. Z. Li, C. C. Chueh, S. T. Williams, W. Jiang, Z. H. Wang, J. S. Yu and A. K. Y. Jen, Adv. Mater., 2014, 26, 5708.

38 Y. Lin, J. Wang, Z.-G. Zhang, H. Bai, Y. Li, D. Zhu and X. Zhan, Adv. Mater., 2015, 27, 1170.

39 Y. Lin, Z.-G. Zhang, H. Bai, J. Wang, Y. Yao, Y. Li, D. Zhu and X. Zhan, Energy Environ. Sci., 2015, 8, 610.

40 S. Holliday, R. S. Ashraf, C. B. Nielsen, M. Kirkus, J. A. Röhr, C.-H. Tan, E. Collado-Fregoso, A.-C. Knall, J. R. Durrant, J. Nelson and I. McCulloch, J. Am. Chem. Soc., 2015, 137, 898.

41 F. Wurthner, Chem. Commun., 2004, 1564.

42 M. R. Wasielewski, J. Org. Chem., 2006, 71, 5051.

43 A. F. Lv, S. R. Puniredd, J. H. Zhang, Z. B. Li, H. F. Zhu, W. Jiang, H. L. Dong, Y. D. He, L. Jiang, Y. Li, W. Pisula, Q. Meng, W. P. Hu and Z. H. Wang, Adv. Mater., 2012, 24, 2626.

44 M. C. R. Delgado, E. G. Kim, D. A. da Silva and J. L. Bredas, J. Am. Chem. Soc., 2010, 132, 3375.

45 X. W. Zhan, A. Facchetti, S. Barlow, T. J. Marks, M. A. Ratner, M. R. Wasielewski and S. R. Marder, Adv. Mater., 2011, 23, 268.

46 C. Li and H. Wonneberger, Adv. Mater., 2012, 24, 613.

47 T. L. Ye, R. Singh, H. J. Butt, G. Floudas and P. E. Keivanidis, ACS Appl. Mater. Interfaces, 2013, 5, 11844.

48 R. Singh, E. Aluicio-Sarduy, Z. Kan, T. Ye, R. C. I. MacKenzie and P. E. Keivanidis, J. Mater. Chem. A, 2014, 2, 14348.

49 A. Sharenko, C. M. Proctor, T. S. van der Poll, Z. B. Henson, T. Q. Nguyen and G. C. Bazan, Adv. Mater., 2013, 25, 4403.

50 A. Sharenko, D. Gehrig, F. Laquai and T. Q. Nguyen, Chem. Mater., 2014, 26, 4109.

51 I. A. Howard, F. Laquai, P. E. Keivanidis, R. H. Friend and N. C. Greenham, J. Phys. Chem. C, 2009, 113, 21225.

52 S. Rajaram, R. Shivanna, S. K. Kandappa and K. S. Narayan, J. Phys. Chem. Lett., 2012, 3, 2405.
53 P. E. Keivanidis, I. A. Howard and R. H. Friend, Adv. Funct. Mater., 2008, 18, 3189.

54 V. Kamm, G. Battagliarin, I. A. Howard, W. Pisula, A. Mavrinskiy, C. Li, K. Mullen and F. Laquai, Adv. Energy Mater., 2011, 1, 297.

55 P. E. Hartnett, A. Timalsina, H. S. S. R. Matte, N. J. Zhou, X. G. Guo, W. Zhao, A. Facchetti, R. P. H. Chang, M. C. Hersam, M. R. Wasielewski and T. J. Marks, J. Am. Chem. Soc., 2014, 136, 16345.

56 Q. F. Yan, Y. Zhou, Y. Q. Zheng, J. Pei and D. H. Zhao, Chem. Sci., 2013, 4, 4389-4394.

57 Y. Zhong, M. T. Trinh, R. S. Chen, W. Wang, P. P. Khlyabich, B. Kumar, Q. Z. Xu, C. Y. Nam, M. Y. Sfeir, C. Black, M. L. Steigerwald, Y. L. Loo, S. X. Xiao, F. Ng, X. Y. Zhu and C. Nuckolls, J. Am. Chem. Soc., 2014, 136, 15215-15221.

58 W. Jiang, L. Ye, X. G. Li, C. Y. Xiao, F. Tan, W. C. Zhao, J. H. Hou and Z. H. Wang, Chem. Commun., 2014, 50, 1024-1026.

59 X. Zhang, Z. H. Lu, L. Ye, C. L. Zhan, J. H. Hou, S. Q. Zhang, B. Jiang, Y. Zhao, J. H. Huang, S. L. Zhang, Y. Liu, Q. Shi, Y. Q. Liu and J. N. Yao, Adv. Mater., 2013, 25, 5791-5797.

60 Y. Z. Lin, J. Y. Wang, S. X. Dai, Y. F. Li, D. B. Zhu and X. W. Zhan, Adv. Energy Mater., 2014, 4, 1400420.

61 J. Roncali, P. Leriche and A. Cravino, Adv. Mater., 2007, 19, 2045.

62 B. A. Gregg, J. Phys. Chem. Lett., 2011, 2, 3013.

63 A. L. Kanibolotsky, I. F. Perepichka and P. J. Skabara, Chem. Soc. Rev., 2010, 39, 2695.

64 Y. Z. Lin, P. Cheng, Y. F. Li and X. W. Zhan, Chem. Commun., 2012, 48, 4773-4775.

65 Y. Z. Lin, Y. F. Wang, J. Y. Wang, J. H. Hou, Y. F. Li, D. B. Zhu and X. W. Zhan, Adv. Mater., 2014, 26, 5137.

66 Y. H. Liu, C. Mu, K. Jiang, J. B. Zhao, Y. K. Li, L. Zhang, Z. K. Li, J. Y. L. Lai, H. W. Hu, T. X. Ma, R. R. Hu, D. M. Yu, X. H. Huang, B. Z. Tang and H. Yan, Adv. Mater., 2015, 27, 1015.

67 K. V. Rao, R. Haldar, C. Kulkarni, T. K. Maji and S. J. George, Chem. Mater., 2012, 24, 969.

68 G. Y. Li and Z. G. Wang, J. Phys. Chem. C, 2013, 117, 24428. 69 G. Y. Li and Z. G. Wang, Macromolecules, 2013, 46, 3058.

70 H. Langhals, C. Wagner and R. Ismael, New J. Chem., 2001, 25, 1047.

71 C. M. Pochas, K. A. Kistler, H. Yamagata, S. Matsika and F. C. Spano, J. Am. Chem. Soc., 2013, 135, 3056.

72 L. J. Huo, S. Q. Zhang, X. Guo, F. Xu, Y. F. Li and J. H. Hou, Angew. Chem., Int. Ed., 2011, 50, 9697.

73 W. J. E. Beek, M. M. Wienk, M. Kemerink, X. N. Yang and R. A. J. Janssen, J. Phys. Chem. B, 2005, 109, 9505.

74 M. Vosgueritchian, D. J. Lipomi and Z. A. Bao, Adv. Funct. Mater., 2012, 22, 421.

75 Y. L. Chen, W. S. Kao, C. E. Tsai, Y. Y. Lai, Y. J. Cheng and C. S. Hsu, Chem. Commun., 2013, 49, 7702.

76 Y. Y. Jiang, L. H. Lu, M. Y. Yang, C. Zhan, Z. Z. Xie, F. Verpoort and S. Q. Xiao, Polym. Chem., 2013, 4, 5612.

77 R. Z. Wang, Z. Q. Shi, C. C. Zhang, A. D. Zhang, J. Chen, W. W. Guo and Z. Z. Sun, Dyes Pigm., 2013, 98, 450. 
78 C. M. Xue, R. K. Sun, R. Annab, D. Abadi and S. Jin, Tetrahedron Lett., 2009, 50, 853.

79 S. Sengupta, R. K. Dubey, R. W. M. Hoek, S. P. P. van Eeden, D. D. Gunbas, F. C. Grozema, E. J. R. Sudholter and W. F. Jager, J. Org. Chem., 2014, 79, 6655.

80 A. D. Becke, J. Chem. Phys., 1993, 98, 5648.

81 C. T. Lee, W. T. Yang and R. G. Parr, Phys. Rev. B: Condens. Matter Mater. Phys., 1988, 37, 785.

82 J. Pommerehne, H. Vestweber, W. Guss, R. F. Mahrt, H. Bassler, M. Porsch and J. Daub, Adv. Mater., 1995, 7, 551.

83 M. F. Falzon, M. M. Wienk and R. A. J. Janssen, J. Phys. Chem. C, 2011, 115, 3178.

84 E. Verploegen, R. Mondal, C. J. Bettinger, S. Sok, M. F. Toney and Z. A. Bao, Adv. Funct. Mater., 2010, 20, 3519.

85 Y. Q. Zheng, Y. Z. Dai, Y. Zhou, J. Y. Wang and J. Pei, Chem. Commun., 2014, 50, 1591.

86 C. W. Schlenker and M. E. Thompson, Chem. Commun., 2011, 47, 3702 .

87 B. Y. Qi and J. Z. Wang, Phys. Chem. Chem. Phys., 2013, 15, 8972 .
88 D. Credgington and J. R. Durrant, J. Phys. Chem. Lett., 2012, 3, 1465.

89 M. J. Frisch, G. W. Trucks, H. B. Schlegel, G. E. Scuseria, M. A. Robb, J. R. Cheeseman, G. Scalmani, V. Barone, B. Mennucci, G. A. Petersson, H. Nakatsuji, M. Caricato, X. Li, H. P. Hratchian, A. F. Izmaylov, J. Bloino, G. Zheng, J. L. Sonnenberg, M. Hada, M. Ehara, K. Toyota, R. Fukuda, J. Hasegawa, M. Ishida, T. Nakajima, Y. Honda, O. Kitao, H. Nakai, T. Vreven, J. A. Montgomery, Jr., J. E. Peralta, F. Ogliaro, M. Bearpark, J. J. Heyd, E. Brothers, K. N. Kudin, V. N. Staroverov, T. Keith, R. Kobayashi, J. Normand, K. Raghavachari, A. Rendell, J. C. Burant, S. S. Iyengar, J. Tomasi, M. Cossi, N. Rega, J. M. Millam, M. Klene, J. E. Knox, J. B. Cross, V. Bakken, C. Adamo, J. Jaramillo, R. Gomperts, R. E. Stratmann, O. Yazyev, A. J. Austin, R. Cammi, C. Pomelli, J. W. Ochterski, R. L. Martin, K. Morokuma, V. G. Zakrzewski, G. A. Voth, P. Salvador, J. J. Dannenberg, S. Dapprich, A. D. Daniels, O. Farkas, J. B. Foresman, J. V. Ortiz, J. Cioslowski and D. J. Fox, Gaussian 09, Revision A.1, Gaussian, Inc., Wallingford CT, 2009. 